ORIGINAL ARTICLE

\title{
Skilled Antenatal Care Service Utilization and Its Association with the Characteristics of Women's Health Development Team in Yeky District, South-West Ethiopia: A Multilevel Analysis
}

\author{
Melese Girmaye $^{1}$, Yifru Berhan ${ }^{2}$
}

\begin{abstract}
BACKGROUND: In response to high maternal and perinatal morbidities and mortalities in Ethiopia, "Women's Health Development Army" was established to enhance utilization of skilled maternity services including antenatal care (ANC). However, its effect on skilled ANC service utilization is not well measured. Our study was aimed to assess skilled antenatal care service utilization and its association with the characteristics of women's health development team (WHDT).

METHODS: A community based cross sectional study was conducted from January to February 2015. A multi-stage cluster sampling technique was applied, and a total of 748 women (15-49 years) who gave birth in one year preceding the study were included in the study. Data were entered into EPI info version 7 statistical software and exported to STATA version 11 for analysis. Bivariate and multilevel mixed effects analysis techniques were applied to check for association of selected independent variables with utilization of skilled ANC.

RESULTS: About $71 \%$ women received skilled ANC service at least once. A significant heterogeneity was observed between WHDTs for skilled ANC utilization. Level-1 predictors of skilled ANC utilization were: preference of skilled personnel (AOR=11.0; 95\%, CI, 3.02-40.04), awareness about places where to get skilled providers $(A O R=51.6$; 95\% CI, 13.92-,190.97) and listening to radio (AOR=5.7; 95\% CI, 1.4621.94). Distance of WHDT within $2 \mathrm{~km}$ radius from the nearest health facility $(\mathrm{HF})$ was the only level-2 significant predictor of skilled ANC service utilization (AOR=8.28; 95\% CI, 1.08-62.20).

CONCLUSIONS: Skilled ANC service utilization is the joint effect of individual and WHDT characters. Awareness and perception creation towards skilled maternity service utilization need to be enhanced. Facilities and transport services should be more accessible towards WHDTs.

KEYWORDS: community based, cross sectional study, Ethiopia, multilevel analysis, skilled antenatal care service, women's health development team
\end{abstract}

DOI: http://dx.doi.org/10.4314/ejhs.v26i4.9

\section{INTRODUCTION}

According to Ethiopian demographic and health surveys (EDHS) 2011, the maternal mortality ratio and perinatal mortality rate were estimated to as 676/100,000 live births, and 46/1000 total births, respectively, which were among the highest in Sub-Saharan African Countries (1-5). The low antenatal care (ANC) coverage has probably contributed to the high maternal and perinatal deaths in Ethiopia (6-11). Although the World Health Organization (WHO) recommended a minimum of 4 ANC visits to all pregnant women, EDHS 2011 and mini EDHS 2014 reported that only $19 \%$ and $32 \%$, respectively, had 4 visits for ANC service, which were the least among the majority of the Sub-Saharan African Countries (3, $6,12,13)$.

\footnotetext{
${ }^{1}$ Department of Public Health, College of Medical and Health Sciences, Wollega University

${ }^{2}$ Chief Executive Director with Vice-President Rank, College of Health Sciences, Addis Ababa University

Corresponding Author: Melese Girmaye, Email: melesegirmaye @ gmail.com
} 
Another challenge in the provision of quality ANC service in Ethiopia has been the time pregnant women receive their first ANC. WHO recommends that the first ANC follow-up should be received in the first trimester. The proportion of women who made the first ANC visit before the fourth month of pregnancy, however, were only $11 \%$ and $17 \%$ in the 2011 and 2014 surveys, respectively. The median age of pregnancy at the time of the first ANC visit was about 5 months $(3,12,14-16)$.

In response to this challenge, the government of Ethiopia has established what is called "Women's Health Development Army (WHDA)" at the community level, since 2011 in several districts across the country. The smallest unit is made up of 6 women (one of the women is a leader, probably trainer and reporter). About 5-6 units form a team, and each team is composed of about 30 households in which all women of child bearing age are included, and the main task is to enhance utilization of skilled maternity service, including ANC. Each WHDA and their team (WHDT) are linked with local health extension workers, the nearby health center and district health office. However, little is known about the association between the establishment of this army and skilled ANC service utilization. No systematic evaluation has been made since its establishment in any part of the country (17).

In other countries, with a similar approach ("The Women's Group"), several studies demonstrated that involving the community in identifying, planning and solving their own problem has positively changed maternal and neonatal health (18-22).

Therefore, measuring the role of activities and characteristics of WHDTs on skilled ANC utilization was a priority area to identify its impact on ANC utilization. The purpose of this study was thus to assess the skilled ANC service utilization and its Association with the characteristics of WHDT.

\section{METHODS}

\section{Study design and setting}

A community based cross-sectional study was conducted over January-February 2015 by including women of reproductive age (15-49 years) at Yeky district, Sheka Zone, South West Ethiopia. The district is located at about $562 \mathrm{kms}$ far from the capital, Addis Ababa. In 2014, the total number of women aged 15-49 years in the district was estimated to be 39,680 . About $96 \%$ of its inhabitants are living in rural area, and agriculture is the main means of livelihood.

\section{Study population and sampling technique}

Women aged 15-49 years who gave birth in one year preceding the study in the randomly selected seven kebeles were included in the study, irrespective of their birth outcome. This study excluded women who were seriously ill, could not respond to questions, could not hear or speak and had severe psychiatric problems during the time of data collection.

Sample size was calculated using single population proportion formula and Epi-Info version-7 statistical software based on the following assumptions: margin of error of $5 \%$, level of significance of $5 \%$, design effect of 2 , non-response rate of $10 \%$, confidence level of $95 \%$ and proportion for at least one skilled antenatal care of $35.9 \%$ (12). Accordingly, the total sample size was 778 .

Sample size for rural and urban stratum was calculated using proportionate allocation to the size of population in the respective areas. The "kebeles" are the lower administrative units with a size of about 1000 households (5000 population) which are further structured into WHDTs.

Cluster sampling technique was used to select the study population. The kebeles with their WHDT (clusters) were selected randomly. Accordingly, seven (five rural and two urban) kebeles with a total of 380 WHDT were selected, and 748 eligible mothers were identified and interviewed.

\section{Data collection}

The data collection was done using a structured and pretested interview questionnaires through a house-to-house visit. The questionnaires were developed based on the standard demographic and health survey (DHS) questionnaires, initially in English, and then translated into the local language, then back to English to check for consistency. Socio-demographic, accessibility, perceived needs (benefits) and WHDT related 
characteristics were included in the questionnaires.

The questionnaires were pretested with 80 eligible women from two kebeles of another district having similar socio-cultural characteristics with the study area. A total of 35 qualified data collectors and 14 supervisors (5 data collectors and 2 supervisors for each kebele) were deployed. Data collectors were teachers and $12^{\text {th }}$ grade complete students, who were living in the study area. Supervisors were all female experienced diploma mid wife nurses.The principal investigator followed up the whole data collection process for completeness, validity and reliability.

\section{Data management and analysis procedures}

After appropriate coding, the data were entered into EPI Info Version 7 statistical software and exported to STATA version 11 for analysis. The predictors of skilled ANC service utilization were assessed separately using multilevel binary logistic regression analysis to determine the direct effect of individual and group-level (WHDT) explanatory variables on individual outcome variables, and to determine if the explanatory variables at the group level served as moderators of individual-level relationships.

Frequencies and cross tabulations were made using our independent predictor variables. The multilevel analysis was started from the intercept only (null) model to test the null hypothesis that there was no variation in skilled ANC service utilization between WHDTs.

Characteristics of the women were considered as individual level (level-1 predictors) and characteristics of the WHDTs were taken as group level (level-2 predictors). For our dependent variable, we estimated two models: the null model (intercept only model), an empty model with no independent variables and a full model that contains both level-1 and level-2 predictors.

The full model was a random intercept model. The null model was used to estimate the overall $\log$ of odds of the outcome variables across all individual and group level variables. It was also used to check the significance of association of the outcome variables with all individual and group level variables (fixed effects) and to estimate the intra-class correlation coefficient (Rho). Intra-class correlation coefficient (ICC) is an extent of the between classes variation influencing individual level outcomes (random effects).

The ICC informs the researcher whether the variation in the scores is primarily within or between groups. Binary dependent variables in multilevel logistic distributions lack inherent scales since mean and level-1 residual variance are unknown. Distribution of level-1 residual variance is standardized and fixed in the logistic distribution with mean of 0 and variance of $\pi^{2} / 3$ $\approx 3.29$. Accordingly, for a two-level logistic random intercept model with an intercept variance of $\sigma^{2} \mathrm{u} 0$, the intra-class correlation coefficient $(\rho)$ is:

$\rho=\sigma^{2} \mathrm{u} 0 / \sigma^{2} \mathrm{u} 0+3.29$.

The Bivariate and multilevel mixed effects logistic regression analysis were made on the full random intercept model. At Bivariate analysis, fixed estimate variables with $p$-values of less than 0.25 and performance level of WHDTs were employed for the multi-level analysis.

The adjusted odds ratios of the level-2 variances were utilized to decide the presence of association between the dependent and independent variables for which their respective $95 \%$ confidence levels and p-values were determined.

\section{Ethical considerations}

Ethical clearance was secured from the Institutional Review Board (IRB) of Hawassa University, College of Medicine and Health Sciences. Permission letters were also obtained from zonal and district health offices before data collection. During data collection, study participants were asked for verbal consents and were informed to interrupt the interview at any time on their desire. To ensure confidentiality, code numbers were used to show results, and all questionnaires were kept locked. The privacy of the study participants was also maintained by interviewing them individually.

\section{Operational definitions}

Skilled ANC service utilization: antenatal care service use by mothers at least once at health center, hospital and or private clinic during the pregnancy of their last birth. 
Women's health development team (WHDT): A team composed of six (6) 1 to 5 reproductive age women networking (each team with about 30 households) aimed at enhancing skilled maternity service utilization and other socioeconomic activities.

Best performing WHDTs: WHDTs graded as "A" as if all households have achieved 91\%$100 \%$ of all the seventeen health extension packages.

Good performing WHDTs: WHDTs graded as "B" as if all households have achieved $81 \%-90 \%$ of all the seventeen health extension packages.

Poor performing WHDTs: WHDTs graded as "C" as if all households have achieved less than $80 \%$ of all the seventeen health extension packages.

Self sustained WHDTs: availability of enough production (food or cash crops) for feeding population in the village (WHDT).

\section{RESULTS}

\section{Socio-demographic characteristics}

A total of 748 women aged 15-49 years who gave birth in one year preceding the study were interviewed. The response rate was $96.1 \%$ for the planned sample and $100 \%$ for the interviewed participants. The majority of the respondents $(84.5 \%)$ were rural dwellers. Most participants $(97.6 \%)$ were ever married (married or divorced). At the time of data collection, the majority (32.9\%) were between 25-29 years old, and $6.7 \%$ were teenagers with the mean age of $25.8 \pm 5.3$ years and with a range of $16-46$ years.

The majority of the study participants were Protestant Christians (62.3\%) and house wives $(92.1 \%)$. Keffa, Amhara and Bench were the dominant ethnic groups accounting for $27.5 \%$, $19.1 \%$ and $17.9 \%$, respectively. Regarding the educational level, $45.7 \%$ did not attend any formal education, and $5.2 \%$ attended secondary and above level of education.

About $60 \%$ of the respondents households had about 10 USD or less average monthly income. About $35 \%$ and $19 \%$ of the respondents listen to radio and watch television, respectively (Table 1).

\section{Obstetrics and perceived needs (benefits) related characteristics}

Three hundred fifty (46.8\%) mothers were teenagers when they gave birth to their first baby. The mean and SD age at the first birth was $19.9 \pm 2.6$ years. More than half $(53.9 \%)$ of the respondents were para II - IV.

Six hundred sixty-five (88.9\%) respondents had visited health facilities for ANC services at least once for the their last birth. Among these, 436(65.6\%) had received ANC services 4 and above times.

From the total respondents, 531(71\%) [P $(95 \% \mathrm{CI})=71 \%(67.8 \%, 74.3 \%)]$ received skilled ANC at least once for their last birth. The majority of the respondents $(65.6 \%)$ received their first ANC for their last birth between 4-6 months while 172 (25.9\%) had received before 3 months.

Regarding their reasons to visit HFs during pregnancy of their last birth, 611(91.9\%), $583(87.7 \%)$ and $82(12.3 \%)$ respondents reported to check their own general health, for their fetal wellbeing and to know the fetal position, respectively, while $40(6 \%)$ and $16(2.1 \%)$ respondents reported that it was for vaccination and to deliver HIV free baby for the future, respectively. Twenty four $(3.6 \%)$ respondents reported that their reason to visit HFs was to get delivery services in the health facilities in the future.

Regarding their sources of knowledge to seek ANC, 414 (62.3\%) respondents reported that it was from health extension workers (HEWs) that they obtained awareness. Of those who did not have any ANC visit for the their last birth, $71.1 \%$ reported that it was because they were not aware of the importance of ANC follow up, while $13.3 \%$ and $12 \%$ reported that it was because the HF was too far and lack of transport, respectively. The majority $(66.2 \%)$ of the respondents preferred skilled personnel for their ANC services, and 518 (69.3\%) respondents had awareness on places where to get skilled providers. 
Table 1: Selected socio-demographic individual level characteristics of women who gave birth in one year preceding the study, Yeky District, 2015. $(\mathrm{N}=748)$

\begin{tabular}{|c|c|c|c|}
\hline Background characteristics & Number (\%) & $\begin{array}{l}\text { Background } \\
\text { characteristics }\end{array}$ & Number (\%) \\
\hline $\begin{array}{ll}\text { Residence: } & \text { Urban } \\
& \text { Rural }\end{array}$ & $\begin{array}{l}116(15.5) \\
632(84.5)\end{array}$ & $\begin{array}{l}\text { Household monthly } \\
\text { average income in birr: } \\
\leq 200 \\
201-1000 \\
>1000\end{array}$ & $\begin{aligned} 448 & (59.9) \\
217 & (29) \\
83 & (11.1)\end{aligned}$ \\
\hline $\begin{array}{l}\text { Current age in years: } \\
\leq 19 \\
20-24 \\
25-29 \\
30-34 \\
\geq 35\end{array}$ & $\begin{array}{c}50(6.7) \\
241(32.2) \\
246(32.9) \\
121(16.2) \\
90(12)\end{array}$ & $\begin{array}{l}\text { Who usually makes } \\
\text { decisions on the } \\
\text { mother's health } \\
\text { care? (Autonomy): } \\
\text { Woman } \pm \text { husband } \\
\text { Husband } \pm \text { others }\end{array}$ & $\begin{array}{l}251(33.6) \\
497(66.4)\end{array}$ \\
\hline $\begin{array}{l}\text { Ethnicity: } \\
\text { Keffa } \\
\text { Amhara } \\
\text { Bench } \\
\text { Sheka } \\
\text { Menja } \\
\text { Sheko } \\
\text { Mejengir } \\
\text { Dawuro } \\
\text { Others }\end{array}$ & $\begin{array}{c}206(27.5) \\
143(19.1) \\
134(17.9) \\
95(12.7) \\
70(9.4) \\
34(4.5) \\
18(2.4) \\
18(2.4) \\
30(4)\end{array}$ & $\begin{array}{l}\text { Age when married first } \\
\text { in years }(n=736): \\
\leq 15 \\
16-19 \\
\geq 20\end{array}$ & $\begin{array}{l}137(18.6) \\
420(57.1) \\
179(24.3)\end{array}$ \\
\hline $\begin{array}{l}\text { Religion: } \\
\text { Protestant } \\
\text { Orthodox } \\
\text { Muslim } \\
\text { Others }\end{array}$ & $\begin{array}{l}466(62.3) \\
183(24.5) \\
92(12.3) \\
7(0.9)\end{array}$ & $\begin{array}{l}\text { Parity: } \\
1 \\
2-4 \\
5 \text { and above }\end{array}$ & $\begin{array}{l}224(29.9) \\
403(53.9) \\
121(16.2)\end{array}$ \\
\hline $\begin{array}{l}\text { Marital status: } \\
\text { Single } \\
\text { Married } \\
\text { Divorced }\end{array}$ & $\begin{aligned} 18 & (2.4) \\
715 & (95.6) \\
15 & (2)\end{aligned}$ & $\begin{array}{l}\text { Maternal education: } \\
\text { No formal education } \\
\text { Primary education(1-8) } \\
\text { Secondary education and } \\
\text { above }\end{array}$ & $\begin{array}{c}342(45.7) \\
367(49.1) \\
39(5.2)\end{array}$ \\
\hline $\begin{array}{l}\text { Husband education }(\mathbf{n}=\mathbf{7 1 5}) \text { : } \\
\text { No formal education } \\
\text { Primary education }(1-8) \\
\text { Secondary education and } \\
\text { above }\end{array}$ & $\begin{array}{r}188(26.3) \\
451(63.1) \\
76(10.6)\end{array}$ & $\begin{array}{l}\text { Listen to radio: } \\
\text { Yes } \\
\text { No }\end{array}$ & $\begin{array}{l}259(34.6) \\
489(65.4)\end{array}$ \\
\hline
\end{tabular}

Most of the study participants (70.8\%) had awareness on danger symptoms of pregnancy, and $96(18.3 \%)$ respondents reported that they faced at least one complication during previous pregnancies or child births. Half of the respondents $(50 \%)$ were from good performing 
WHDTs; 302 (40.4\%) were from best performing and the remaining $72(9.6 \%)$ were from poor performing WHDTs. WHDTs with the majority $(40.8 \%)$ of the respondents were far from their nearest HF with skilled care by more than $5 \mathrm{kms}$ while WHDTs with 213 (28.5\%) respondents were within $2 \mathrm{kms}$ radius of their nearest HF with skilled care. The main source of income for the WHDTs with most respondents (78.1\%) was farming. WHDTs with 388 (51.9\%) respondents had main roads heading to the nearest health center or hospital while the remaining did not have main roads (Table 2).

Table 2: Utilization of skilled antenatal care services using selected individual and group level characteristics in Yeky district, 2015.

\begin{tabular}{|c|c|c|c|}
\hline Characteristics & Category & $\mathrm{N}$ & $\begin{array}{l}\text { Number (percent) of women reporting } \\
\text { skilled ANC services: }\end{array}$ \\
\hline Residence & $\begin{array}{l}\text { Urban } \\
\text { Rural }\end{array}$ & $\begin{array}{l}116 \\
632\end{array}$ & $\begin{array}{l}113(97.4) \\
418(66.1)\end{array}$ \\
\hline Maternal education & $\begin{array}{l}\text { Formal education } \\
\text { No formal education }\end{array}$ & $\begin{array}{l}406 \\
342\end{array}$ & $\begin{array}{l}323(79.6) \\
208(60.8)\end{array}$ \\
\hline Husband education & $\begin{array}{l}\text { Formal education No } \\
\text { formal education }\end{array}$ & $\begin{array}{l}527 \\
188\end{array}$ & $\begin{array}{l}394(74.8) \\
112(59.6)\end{array}$ \\
\hline $\begin{array}{l}\text { ANC in previous } \\
\text { pregnancy }\end{array}$ & $\begin{array}{l}\text { Yes } \\
\text { No }\end{array}$ & $\begin{array}{l}359 \\
165\end{array}$ & $\begin{array}{l}253(70.5) \\
93(56.4)\end{array}$ \\
\hline $\begin{array}{l}\text { Complications } \\
\text { during previous } \\
\text { pregnancies }\end{array}$ & $\begin{array}{l}\text { Yes } \\
\text { No }\end{array}$ & $\begin{array}{l}96 \\
428\end{array}$ & $\begin{array}{l}65(67.7) \\
281(65.7)\end{array}$ \\
\hline $\begin{array}{l}\text { Preferred ANC } \\
\text { services }\end{array}$ & $\begin{array}{l}\text { Yes } \\
\text { No }\end{array}$ & $\begin{array}{l}495 \\
253\end{array}$ & $\begin{array}{r}449(90.7) \\
82(32.4)\end{array}$ \\
\hline $\begin{array}{l}\text { Have awareness on } \\
\text { places to get skilled } \\
\text { providers for ANC }\end{array}$ & $\begin{array}{l}\text { Yes } \\
\text { No }\end{array}$ & $\begin{array}{l}518 \\
230\end{array}$ & $\begin{array}{l}470(90.7) \\
61(26.5)\end{array}$ \\
\hline Listen to radio & $\begin{array}{l}\text { Yes } \\
\text { No }\end{array}$ & $\begin{array}{l}259 \\
489\end{array}$ & $\begin{array}{l}232(89.6) \\
299(61.1)\end{array}$ \\
\hline $\begin{array}{l}\text { Average distance of } \\
\text { WHDT from the } \\
\text { nearest HF with } \\
\text { skilled care (KMs) }\end{array}$ & $\begin{array}{l}\leq 2 \\
3-5 \\
>5\end{array}$ & $\begin{array}{l}213 \\
230 \\
305\end{array}$ & $\begin{array}{l}203(95.3) \\
143(62.2) \\
185(60.7)\end{array}$ \\
\hline $\begin{array}{l}\text { Self-sustained } \\
\text { WHDT }\end{array}$ & $\begin{array}{l}\text { Yes } \\
\text { No }\end{array}$ & $\begin{array}{l}592 \\
156\end{array}$ & $\begin{array}{l}442(74.7) \\
89(57.1)\end{array}$ \\
\hline Main road & $\begin{array}{l}\text { Yes } \\
\text { No }\end{array}$ & $\begin{array}{l}388 \\
360\end{array}$ & $\begin{array}{l}308(79.4) \\
223(61.9)\end{array}$ \\
\hline $\begin{array}{l}\text { Performance level } \\
\text { of WHDT }\end{array}$ & $\begin{array}{l}\text { Best performing } \\
\text { Good performing } \\
\text { Poor performing } \\
\text { Total }\end{array}$ & $\begin{array}{r}302 \\
374 \\
72 \\
748\end{array}$ & $\begin{array}{l}228(75.5) \\
242(64.7) \\
61(84.7) \\
531(71)\end{array}$ \\
\hline
\end{tabular}




\section{Multilevel mixed effects logistic regression analysis}

The results showed that there was significant heterogeneity between WHDTs with regard to skilled ANC utilization. The estimated betweenclusters variance for skilled ANC utilization was 4.98 with $95 \%$ confidence intervals of 3.01Table 3: Parameter coefficients of the intercept only (null) model in using skilled antenatal care services, Yeky district, 2015

\begin{tabular}{ll}
\hline & Skilled ANC service \\
\hline Level 2 variance: VAR (_cons) & $4.985^{*}(3.011,8.253)$ \\
Intra- cluster correlation coefficient, & 0.6024 \\
Rho & 706 \\
Deviance (-2 log likelihood) & \\
\hline
\end{tabular}

*Significant

As shown in the multilevel analysis, preference of skilled personnel, awareness about places where to get skilled services and listening to radio were the level-1 significant predictors of skilled ANC utilization while distance of WHDT within $2 \mathrm{kms}$ radius from the nearest HF with skilled care was the only level-2 significant predictor of skilled ANC utilization.

Accordingly, women who preferred skilled personnel for ANC were 11 times more likely to utilize skilled ANC as compared to those who did not prefer skilled personnel (AOR $=11 ; 95 \%$ CI, 3.02, 40.04). Women who were aware of places where skilled ANC would be received were 51.6 times more likely to utilize skilled
8.25, demonstrating significant variation among the 261 WHDTs for skilled ANC utilization. Accordingly, the ICC in the null model for skilled ANC utilization was $60.2 \%$. In other words, $60.2 \%$ of the total variance for skilled ANC utilization was due to variation between clusters (WHDTs) (Table 3).
ANC as compared to those women who were not aware of the places $(\mathrm{AOR}=51.6 ; 95 \% \mathrm{CI}$, 13.92, 190.97).

The odds of utilizing skilled ANC was 5.7fold higher in women who listened to radio as compared to those women who did not listen to radio $(\mathrm{AOR}=5.7 ; 95 \% \mathrm{CI}, 1.46,21.94)$. The study also showed that women from WHDTs within $2 \mathrm{kms}$ radius of the nearest HF providing skilled care were 8.2 times more likely to utilize skilled ANC as compared to women from WHDTs within $5 \mathrm{kms}$ and above radius of the nearest $\mathrm{HF}$ providing skilled care $(\mathrm{AOR}=8.2$; 95\% CI, 1.08, 62.20) (Table 4). 
Table 4: Bivariate and multilevel analysis by predictors of skilled antenatal care service utilization

\begin{tabular}{|c|c|c|c|c|}
\hline Characteristics & $\mathrm{N}$ & $\begin{array}{l}\text { Crude OR } \\
(95 \% \text { CI })\end{array}$ & $\begin{array}{l}\text { Adjusted OR } \\
(95 \% \mathrm{CI})\end{array}$ & $\begin{array}{l}\text { P value } \\
\text { (AOR) }\end{array}$ \\
\hline Residence: Urban & 116 & $34.39(6.35,186.24)$ & $1.01(0.04,28.72)$ & 0.995 \\
\hline Rural & 632 & 1 & 1 & \\
\hline \multicolumn{5}{|l|}{ Maternal education: } \\
\hline Formal education & 406 & $2.65(1.59,4.42)$ & $1.32(0.49,3.58)$ & 0.581 \\
\hline No formal education & 342 & 1 & 1 & \\
\hline \multicolumn{5}{|l|}{ Husband education: } \\
\hline Formal education & 527 & $2.00(1.15,3.51)$ & $1.61(0.60,4.35)$ & 0.348 \\
\hline No formal education & 188 & 1 & 1 & \\
\hline \multicolumn{5}{|c|}{$\begin{array}{l}\text { *ANC follow up for previous } \\
\text { pregnancy: }\end{array}$} \\
\hline Yes & 359 & $6.11(2.86,13.04)$ & $0.87(0.30,2.49)$ & 0.792 \\
\hline No & 165 & 1 & 1 & \\
\hline \multicolumn{5}{|c|}{$\begin{array}{l}\text { Complications during previous } \\
\text { pregnancies or births: }\end{array}$} \\
\hline Yes & 96 & $1.78(0.80,3.95)$ & $1.12(0.32,3.89)$ & 0.856 \\
\hline No & 428 & 1 & 1 & \\
\hline \multicolumn{5}{|c|}{ Skilled personnel preferred for } \\
\hline ANC services: Yes & 495 & $54.25(24.43,120.46)$ & $11.00(3.02,40.04)$ & 0.000 \\
\hline No & 253 & 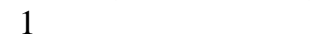 & 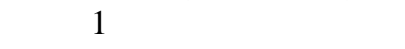 & \\
\hline \multicolumn{5}{|l|}{$\begin{array}{l}\text { Awareness on places to get } \\
\text { skilled providers for ANC: }\end{array}$} \\
\hline Yes & 518 & $58.03(27.51,122.41)$ & $51.55(13.92,190.97)$ & 0.000 \\
\hline No & 230 & 1 & 1 & \\
\hline \multicolumn{5}{|l|}{ Listen to radio: } \\
\hline Yes & 259 & $7.19(3.69,14.00)$ & $5.66(1.46,21.94)$ & 0.012 \\
\hline No & 489 & 1 & 1 & \\
\hline \multicolumn{5}{|l|}{$\begin{array}{l}\text { WHDT characters: } \\
\text { Distance of WHDT from } \\
\text { nearest HF with skilled care }\end{array}$} \\
\hline \multirow{3}{*}{$\begin{array}{l}\leq 2 \\
3-5 \\
>5\end{array}$} & 213 & $19.22(6.53,56.57)$ & $8.18(1.08,62.20)$ & 0.042 \\
\hline & 230 & $1.01(0.50,2.03)$ & $0.51(0.15,1.67)$ & 0.264 \\
\hline & 305 & 1 & 1 & \\
\hline \multicolumn{5}{|l|}{ Self sustained WHDT: } \\
\hline Yes & 592 & $2.67(0.95,7.51)$ & $0.37(0.08,1.83)$ & 0.225 \\
\hline No & 156 & 1 & 1 & \\
\hline \multicolumn{5}{|l|}{ Main road to nearest $\mathrm{HF}$} \\
\hline Yes & 388 & $3.92(1.67,9.21)$ & $0.81(0.22,3.01)$ & 0.747 \\
\hline No & 360 & 1 & & \\
\hline \multicolumn{5}{|l|}{ Performance level of WHDT: } \\
\hline Best Performing & 302 & $0.63(0.18,2.16)$ & $0.46(0.04,5.02)$ & 0.527 \\
\hline Good performing & 374 & $0.34(0.11,1.09)$ & $0.21(0.02,2.15)$ & 0.188 \\
\hline Poor performing & 72 & 1 & 1 & \\
\hline \multirow[t]{3}{*}{ Random part of the model: } & \multirow{3}{*}{\multicolumn{2}{|c|}{$\begin{array}{l}\text { VAR (cons) i.e. Level-2 variance } \\
\text { Rho, intra-class correlation coefficient. } \\
\text { Deviance (-2 log likelihood), } G^{2}\end{array}$}} & $6.11(2.79,13.40)$ & \\
\hline & & & 0.65 & \\
\hline & & & 278 & \\
\hline
\end{tabular}

*Antenatal care follow up for previous pregnancy just before the last birth 


\section{DISCUSSION}

In this study, a multilevel modeling technique allowed us to assess variation in the dependent variable at several levels. Specifically, the utilization of skilled ANC by individual women was dependent on the joint effect of individual and WHDT level factors.

The ICC indicated that the contribution of the unobserved group (WHDT) level characteristics to skilled ANC utilization was more than three-fifths higher. In the random intercept model as well, variance among WHDT was statistically significant indicating how important controlling confounding variables at different levels, which may have false associations with the dependent variable. Previous studies based on similar analysis also showed similar findings (23-28).

Having awareness about health facilities where to get skilled ANC was an important positive predictor for skilled ANC service utilization in our study. Studies done in North West Ethiopia and Pakistan showed similar associations $(23,29)$. Other studies also revealed that exposure to mass media has significant effect towards positive attitudinal changes in using skilled maternity services (4, 30-33).

The result of our study consistently depicted that those women who preferred skilled personnel for their ANC were more likely to utilize skilled ANC than those who did not prefer skilled providers.This implicates that attitudinal changes towards seeking skilled ANC services through repeated and multisectoral community and facility based educations could bring positive effects on skilled ANC service utilization, which was also well noted by previous investigators elsewhere in the country $(23,34,35)$.

The independent association of distance of WHDT within $2 \mathrm{kms}$ radius from the nearest HF with skilled ANC utilization may indicate the significance of geographic accessibility of HFs for better utilization of maternity care. Previous studies have shown that distance from HFs and lack of transport are important deterring factors that hinder mothers from seeking skilled maternity services including ANC (14, 36-43).

Regarding maternal and husband education, Both primary and above level of maternal or husband education were not significantly associated with skilled ANC utilization during multi level mixed effects analysis. This finding was contradictory with most researches done, which indicated positive and highly significant associations $(4,13,23,33,37,44)$.

In our study, the effect of education could probably be controlled by the effects of perception and awareness related variables. This could also be due to the low sample size to detect the effect of education. The Bivariate and multilevel mixed effects analysis did not show statistically significant association between performance level of WHDTs and skilled ANC utilization of their respective women.

This implicates that it was not the performance level of WHDTs that brought difference between WHDT groups by skilled ANC utilization. Rather, the difference was due to accessibility of health facilities, presence of mass media like local FM radios and variation in awareness creation activities about the importance of skilled ANC services. Our finding could also imply the need for reevaluating the measurement tools for classifying WHDTs by performance.

Self-sustainability of WHDTs with food or cash crops was not also significantly associated with skilled ANC utilization. Its effect might be controlled by distances of WHDTs from the nearest HF. Most supported WHDTs were from urban and semi-urban areas very close to the nearest HFs with skilled care. On the other hand, women very far from HFs with skilled services might not be aware of the importance of skilled ANC and facilities where they could get skilled care, which is in agreement with one study done in North West Ethiopia (23).

More proportion of the between WHDT variance by skilled ANC utilization was explained by the random intercept model. The between WHDT variance significantly increased.

This study has several limitations. Some respondents might not properly identified the skilled personnel (doctors, midwives, nurse) and HEWs. Some women might have difficulty of recalling the ANC related events. In a crosssectional study, it could also be difficult to exhaust all possible associated factors. 
In conclusion, skilled ANC utilization was the joint effect of individual and WHDT level characteristics. Individual level predictors were stronger than group level predictors. There was no statistically significant association between performance level of WHDTs and skilled ANC utilization.

Community awareness and perception creation activities towards skilled ANC utilization need to be strengthened. Moreover, HFs and transportation services need to be more accessible for the community. Implementation and evaluation strategies of "WHDTs" activities need to be revised.

\section{ACKNOWLEDGMENT}

We would like to thank Dr. Eskindir loha, Dr. Samson G/medhin and Dr. Ayalew Astatike for their technical support. Our special thank goes to Dr. Abebaw Gebeyehu for his important contribution in analyzing the data. We would also like to thank all the data collectors, study participants and Mizan-Teppi university.

\section{REFERENCES}

1. Central Statistical Authority [Ethiopia] and ORC Macro [USA]. 2001. Ethiopia Demographic and Health Survey 2000. Addis Ababa, Ethiopia and Calverton, Mary land, USA: Central Statistical Authority and ORC Macro.

2. Central Statistical Agency [Ethiopia] and ORC Macro [USA]. 2006. Ethiopia Demographic and Health Survey 2005. Addis Ababa, Ethiopia and Calverton, Maryland, USA : Central Statistical Agency and ORC Macro.

3. Central Statistical Agency [Ethiopia] and ICF International. 2012. Ethiopia Demographic and Health Survey 2011. Addis Ababa, Ethiopia and Calverton, Maryland, USA: Central Statistical Agency and ICF International.

4. Mengesha ZB, Biks GA, Ayele TA, Tessema GA. Determinants of skilled attendance for delivery in North West Ethiopia: a community based nested case control study. BMC Public Health, 2013; 13(130):1-6.

5. Woldie M. The death of the mother and her child keeps on bothering developing nations. Ethiop J Health Sci. 2014; 24 (Special issue).

6. Berhan Y.; Berhan A. Antenatal care as a means of increasing birth in the health facility and reducing maternal mortality. Ethiop J Health Sci. 2014 (special issue):93104.

7. Berhan Y.; Berhan A. A meta-analysis of selected maternal and fetal factors for perinatal mortality. Ethiop J Health Sci. 2014 (special issue):55-65.

8. Bloom SS, Lippeveld T, Wypij D. Does antenatal care make a difference to safe delivery? a study in urban Uttar Pradesh,India. Oxford University Press, 1999; 14(1):38-48.

9. Ofori-Atta A, Canavan M, Udry C, Bradley E. Empowerment and adequate use of antenatal care among women in Ghana: a cross-sectional study. BMC Pregnancy and Childbirth 2014; 14(364):1-16.

10. Dairo MD, Owoyokun KE. Factors affecting the utilization of antenatal care services in Ibadan, Nigeria. ARD Journal, 2010; 12(1):3-13.

11. Kirigia J. M.; Mwabu G. M.; Orem J. N.; Muthuri R. D.K. Indirect cost of maternal deaths in the WHO African region in 2010. BMC Pregnancy and Childbirth, 2014; 14(299):1-10.

12. Central Statistical Agency [Ethiopia]. 2014. Ethiopia Mini Demographic and Health Survey 2014. Addis Ababa, Ethiopia: Central Statistical Agency [Ethiopia].

13. Tarekegn MS, Lieberman SL, Giedraitis V. Determinants of maternal health service utilization in Ethiopia, analysis of 2011 EDHS. BMC Pregnancy and Childbirth, 2014; 14(161): 1-13.

14. Manzi A, Munyaneza F, Mujawase F, et al. Assesing predictors of delayed antenatal care visits in Ruwanda: a secondary analyis of Ruwanda demographic and health survey 2010. BMC pregnancy and childbirth, 2014; 14(290):1-8.

15. Gudayehu TW, Woldeyohannes SM, Abdo AA. Timing and factors associated with first 
antenatal care booking among pregnant mothers in Gondar Town; North West Ethiopia. BMC Pregnancy and Childbirth, 2014; 14(287):1-7.

16. Abosse Z, Woldie M, Ololo S. Factors influencing antenatal care service utilization in Hadiya Zone. Ethiop J Health Sci, 2010; 20(2):75-82.

17. Federal Democratic Republic of Ethiopia. Ministry of Health Quarterly Health Bulletin Report: Policy and Practice. Federal Democratic Republic of Ethiopia, Ministry of Health 2013. http://www.moh.gov.et/documents/2 6765/1612928/FMOH+Journal+Volu me+5/b6ff32c7-1f1f-4fce-a3223a80f80bcad7. Pdf.

18. Wax JR, Lucas FL, Lamont $M$, et al. Maternal and newborn outcomes in planned home birth vs planned hospital births: a meta-analysis. Am J Obstet Gynecol, 2010; 203: 243. e1-8.

19. Kirkwood BR; Manu A.; Asbroek AHS, et al. Effect of the New hints home-visits intervention on neonatal mortality rate and care practices in Ghana: a cluster randomized controlled trial. Lancet, 2013; 381:2184-92.

20. Gogia S, Sachdev SH. Home visits by community health workers to prevent neonatal deaths in developing countries: a systematic review. Bull World Health Organ, 2010; 88:658-66.

21. Prost A, Colbourn T, Seward N, et al. Women's groups practicing participatory learning and action to improve maternal and newborn health in low-resource settings: a systematic review and meta-analysis. Lancet, 2013; 381:1736-46.

22. Tripathy P, Nair N, Barnett S, et al. Effect of a participatory intervention with women's groups on birth outcomes and maternal depression in Jharkhand and Orissa, India: a cluster-randomised controlled trial. The Lancet, 2010; 375(9721):1182 - 92.

23. Worku GA, Yalew WA, Afework FM. Factors affecting utilization of skilled maternal health care in north Gondar Zone, North West Ethiopia: a multilevel analysis.
BMC International Health and Human Rights, 2013; 13(20):1-11.

24. Stella B, Adesegun F. Determinanats of use of maternal health services in Nigerialooking beyond individual and household factors. BMC Pregnancy and Childbirth, 2009; 9 (43):1-13.

25. Debelew GT, Afework MF, Yalew A. W. Factors affecting birth preparedness and complication readiness in Jimma Zone, Southwest Ethiopia: a multilevel analysis. Pan African Medical Journal, 2014; 19 (272):1-14.

26. Sepheri A, Sarma S, Simpson W, Moshiri S. How important are individual, household and commune characteristics in explaining utilization of maternal health services in Vietnam? Social Science and Medicine 2008; 67:1009-17.

27. Tsui A, Ukwuani F, Guilkey D, Angeles G. A comparative multi-level analysis of health program effects on individual use of reproductive and sexual health services. Measure evaluation bulletin, 2003; 6:1-12.

28. Ergano K, Getachew M, Seyum D, Negash K. Determinants of community based maternal health care service utilization in South Omo pastoral areas of Ethiopia. Journal of Medicine and Medical Sciences, 2012; 3(2):112-21.

29. N Nisar, F White. Factors affecting utilization of Antenatal Care among reproductive age group Women (15-49 years) in an urban squatter settlement of Karachi. Journal of Pakistan Medical Association, 2003;53 (2):1-10.

30. Birmeta K, Dibaba Y, Woldeyohannes D. Determinants of maternal health care utilization in Holeta Town, Central Ethiopia. BMC Health Services Research, 2013; 13 (256):1-9.

31. Regassa N. Antenatal and postnatal care service utilization in Southern Ethiopia: a population-based study. African Health Sciences, 2011; 11 (3):390 - 7.

32. Gurmesa T. Antenatal care service utilization and associated factors in Metekel Zone, North West Ethiopia. Ethiop J Health Sci, 2009; 19 (2):111-9.

33. Muchabaiwa L, Mazambani D, Chigusiwa L, Bindu S, Mudavanhu V. Determinants of 
maternal healthcare utilization in Zimbabwe. International journal of economic sciences and applied research, 2012; 5(2):145-62.

34. Yohannes B, Tarekegn M, Paulos W. Mothers' utilization of antenatal care and their satisfaction with delivery services in selected public health facilities of Wolaita Zone, Southern Ethiopia. International jounal of scientific and technology research, 2013; 2(2): 1-12.

35. Hailu M.; Gebremariam A.; Alemseged F.; Deribe K. Birth preparedness and complication readiness among pregnant women in Southern Ethiopia. Plos One, 2011; 6(6):1-7.

36. Mpembeni NMR; Killewo ZJ; Leshabari T.M.; et al. Use pattern of maternal health services and determinants of skilled care during delivery in southern Tanzania: implications for achievements of MDG 5 Targets. BMC Pregnancy and Childbirth 2007; 7(29):1-7.

37. Berhan Y.; Berhan A. A meta-analysis of socio-demographic factors predicting birth in health facility. Ethiop $J$ Health Sci. 2014(special issue): 81-90.

38. Tsegay Y.; Gebrehiwot T.; Goicolea I.; Edin K.; Lemma H.; Sebastian S.M. Determinants of antenatal care and delivery care utilization in Tigray Region, Ethiopia: a cross-sectional study. International Journal for Equity in Health 2013; 12(30):1-10.

39. Tann CJ; Kizza M.; Elliott MA; et al. Use of antenatal services and delivery care in Entebe,Uganda. BMC Pregnancy and Childbirth 2007; 7(23):1-11.

40. Tewodros B.; G/Mariam A.; Dibaba Y. Factors affecting antenatal care utilization in Yem special Woreda, SouthWestern Ethiopia. Ethiop J Health Sci. 2009; 19 (1):45-51.

41. Berhan Y.; Berhan A. Commentary: reasons for persistently high maternal and perinatal mortalities in Ethiopia: part iii-perspective of the "three delays" model. Ethiop J Health Sci.2014 (special issue):137-46.

42. Berehan Y.; Berhan A. Commentary: actions in the pipeline and the way forward to reduce maternal and perinatal mortality in Ethiopia. Ethiop J Health Sci 2014 (Special issue):149-68.

43. Tey NP; Lai SL. Correlates of and barriers to the utilization of health services for delivery in South Asia and Sub-Saharan Africa. The Scientific World Journal 2013; 2013:1-11.

44. Yesuf E. A.; Calderon-Margalit R. Disparities in the use of antenatal care service in Ethiopia over a period of fifteen years. BMC Pregnancy and Childbirth 2013; 13(131):1-10. 